\title{
Work-related Stress and Associated Factors among Academic Staffs at the University of Gondar, Northwest Ethiopia: An Institution- based Cross-sectional Study
}

\author{
Gebisa Guyasa Kabito ${ }^{1 *}$, Sintayehu Daba Wami ${ }^{1}$, Daniel Haile Chercos ${ }^{1}$, \\ Tesfaye Hambisa Mekonnen ${ }^{1}$
}

\footnotetext{
OPEN ACCESS

Citation: Kabito Gebisa, Wami Sintayehu, Chercos Daniel, Mekonnen Tesfaye. Work-related Stress and Associated Factors among Academic Staffs at the University of Gondar, Northwest Ethiopia: An Institution-based Cross-sectional Study. Ethiop J Health Sci.2020;30(2):223.doi:http://dx.doi.org/10 .4314/ejhs.v30 i 2.10

Received: October 9, 2019

Accepted: November 11, 2019

Published: March 1, 2020

Copyright: (C2020 Kabito G., et al. This is an open access article distributed under the terms of the Creative Commons Attribution License, which permits unrestricted use, distribution, and reproduction in any medium, provided the original author and source are credited. Funding: Nil

Competing Interests: The authors declare that this manuscript was approved by all authors in its form and that no competing interest exists.

Affiliation and Correspondence:

${ }^{1}$ Department of Environmental and Occupational Health and Safety, Institute of Public Health, College of Medicine and Health Sciences, University of Gondar, P.O. Box 196, Gondar, Ethiopia

*Email: gebeguyasa4@gmail.com
}

\section{ABSTRACT}

BACKGROUND: Work-related stress is described as a physiological and psychological reaction to the harmful aspects of workplace content. Current evidence indicates that the world of education is a highly stressful occupation. However, in academicians in sub-Saharan African countries, such as Ethiopia, the prevalence and contributing factors are not well studied. This study was, therefore, aimed at filling this gap.

METHODS: A cross-sectional study was conducted from March to April 2018. Stratified sampling technique was used to select 535 study participants. To measure work-related stress, we used the pre-tested and structured self-administered University and College Union stress questionnaire. Finally, a significant association was established at $p<0.05$ and adjusted odds ratio (AOR) with 95\% confidence intervals (CI) in the multivariable model.

RESULTS: The overall prevalence of work-related stress in 12 months was 60.4\% [95\% CI (57.4, 63.5\%)].The multivariable logistic regression analysis showed that smoking cigarette (AOR: 2.84, 95\% CI (1.25, 6.50), high job demand (AOR: 3.27, 95\% CI (2.05, 5.21), low job control (AOR:2.25, 95\% CI (1.21, 4.20) and age $<28$ (AOR:0.25, 95\% CI $(0.10,0.63)$ were the factors associated with work-related stress.

CONCLUSION: The prevalence of work-related stress was high. Furthermore, higher emphasis required on job demand, job control, and cigarette smoking to ease the burden of work-related stress factors. This research, therefore, recommended that other causes of WRS, such as working conditions and further large-scale study, be considered for future research.

KEYWORDS: Academic staff, Work-related stress, University, Ethiopia

\section{INTRODUCTION}

Several scholars have described the term "stress" (1). Workrelated stress (WRS) is described as a physiological and psychological reaction to the harmful aspects of workplace content (2). WRS was commonly recognized as a source of 
stress among the working population, including academics (3).

Beside WHO and ILO reports, recent studies have also shown that the academic world is a highly stressful occupation $(4,5)$. For example, a study in the UK reported that a large proportion of academic and related staff found their work stressful (6). Report from China indicated that almost all of the academic staffs were stressed (7). Correspondingly, the result of a study in India showed that the majority of the academic staffs experienced high levels of stress (8). Moreover, though there is only a small survey in Africa, Zimbabwe (9), Nigeria (10) and Tanzania (11) have reported a high prevalence of stress from higher education academic staff.

WRS is a major problem in occupational health, involving substantial costs for staff, employers and government (12). The European Agency for Safety and Health at Work, for example, noted that over 550 million working days are lost every year in the U.S due to stress (13). The Labor Force Survey (LFS) has also reported a loss of 11.3 million working days of $487,000 \mathrm{UK}$ employees, in 2013/14 (14).WRS is another key public health issue in today's world, since it reduces the efficiency and creativity of academic work, alongside its health, well-being, and morality(15) .

Different researches reported high job demand, low job control, poor job relationships, low social and work support and cigarette smoking as risk factors for work-related stress. Prolonged exposure to all the above stressors can serve the development of several maladjustments. In the first place, manifestation of anger and aggression because of the low-stress resistance are quite usual for the teachers. If the high demands of a teacher's job are not accompanied by a high degree of control over their work and participation in decision-making, stress will result $(16,17)$. Low control over their job was also reported as risk factor for stress. Lack of consultation by management and lack of participation in decisionmaking was a major source of stress for the university staff, resulting in loss of autonomy and control. An individual who has an external locus of control over his/her life is more likely to experience stress $(9,11)$. Moreover, academic staff with poor teacher-student relationships, conflict with students and poor relationships with colleagues are also believed to be highly stressed (7). In addition, cigarette smoking has been also identified as a major work-related stress predictor. Research showed that smoking increases anxiety and tension(18). Although the aforementioned results show a variation in stressors from country to country and by type and size of the institution, they also provide indications of an overall present condition of work-related stress amongst university teachers.

While global stress research is on the rise, the literature available is not comprehensive specifically in addressing work-related stress and associated factors among academic staff, including those in Ethiopia. As of today, very little research has been done among university teachers in Ethiopia, on work-related stress and associated factors. Therefore, this study was intended to fill this gap.

\section{METHODS AND MATERIALS}

Study design, period and description of the settings: A cross-sectional study was conducted between 1 March and 30 April in 2018. The University of Gondar is one of the oldest universities in the country, located in the historic town of Gondar, Ethiopia. There are five campuses: the College of Health and Medicine (CMHS), Tseda, Maraki, AsteTewodros and AtseFasil. There were 2314 academic staff in all campuses.

Study Population, sample size determination and sampling procedure: All academic staff at the University of Gondar and working at a selected campus and having worked at least 6 months before the study were included as part of the study population. Academic staff with critical illness, maternity leave and sabbatical leave were excluded. The sample size was determined using a single population proportion formula, by considering proportion (p) 28.2\% (19), 95\% level of confidence and $4 \%$ margin of error (d):

$n=\frac{(z \alpha / 2) 2 p(1-p)}{d 2}=\frac{(1.96) 2 \times 0.282(1-0.282)}{(0.04) 2}=486$

Considering a $10 \%$ non-response rate, the final sample becomes 535. Stratified sampling technique 
was used to select the study participants from the five campuses of the University of Gondar. The number of sample points was determined by using proportional allocation for each stratum. Accordingly, the numbers of participants from each campus were 82 from Fasil campus, 209 from College of Medicine and Health Sciences, 130 from Maraki Campus, 25 from Agriculture Campus and 89 from Tewodros Campus. Then, the required sample sizes were selected by applying simple random sampling technique using a computer random number generating from each stratum.

Data collection instrument: Data were gathered through a pre-tested and structured selfadministered questionnaire developed through an adaptation from UCU (University and College Union) a Stress Questionnaire, which was initially adopted from both an occupational stress survey and the Management Standards indicator tool for Health and Safety Executives (20). The questionnaire consists of five parts. For the current study, we used the first two parts and the fourth part. The first part contains questions about the demographic characteristics of respondents (gender, age, marital status, academic rank and work experience). The second part consists of 26 items related to stress which were further categorized into two major parts: physiological (18 items) and psychological stress ( 8 items). The fourth part includes six different categories of factors generating work-related stress [((job demand (18items), Job control (9 items), job relationships (9 items), Role ambiguity (9 items), Job changes (10 items) and support (9items))]. We calculated the mean score for all of them. Cigarette smoker:Study participants who smoke one cigarette per day for at least 1 year were considered smoker (20). A Likert scale of 5 types was used to assess work-related stress (rated as either $1=$ never, $2=$ rarely, $3=$ =sometimes, $4=$ often, $5=$ =always), and we took a percentage. The ultimate score was categorized into two with a score of less than $50 \%$ $=($ not stressed $)$ and a score of $50 \%$ and above $=1$ (stressed) (21). The tool has been used in several countries, including African countries, and has been reported as valid and reliable $(9,11)$. Moreover, reliability analysis was performed to ensure that items within each composite were consistent. Internal consistency/reliability was checked by calculating Cronbach's alpha for each of the composites to examine the extent to which respondents answered consistently the theoretically similar items in each composite. Accordingly, in this study, the Cronbach's alpha for physiological (18 items) and psychological (8 items) composites were 0.88 and 0.89 respectively. The reliability coefficient score for the overall questionnaire (26 items) was 0.92. Literature indicates that a value of Cronbach's alpha .60 or greater is assumed to be acceptable (22). Therefore, each of the dimensions was found to have an acceptable reliability.

Data quality control: For both data collectors and supervisors, a half day training on the objective of the study, ethical considerations and content of the questionnaire was provided. Five degree-holding psychiatric nurses working outside the current study area collected data. The supervisors monitored the data collection process daily. The questionnaire was pretested on $5 \%$ of the calculated sample size among academic staff working in a nearby college called "polytechnic College". Improvements were made based on the results of the pretest.

Data management and statistical analysis: Data were entered into EPI-INFO version 7 and exported to SPSS version 20 for analysis. Logistic regression model was used to assess the statistical association between the outcome variable (workrelated stress) and independent variables. In the bivariable logistic regression model, all variables with a p-value of $<0.2$ were entered into multivariable logistic regression model. Hosmer and Lemeshow goodness-of-fit test was used to check the model fitness $(\mathrm{P}>0.05)$. A multi colinearity assumption was checked using the Variance Inflation Factor (VIF $<5$ ). Finally, a significant association was established at $p<0.05$ and adjusted odds ratio (AOR) with 95\% confidence intervals $(\mathrm{CI})$ in the multivariable model. In the model, all variables were categorical variables.

Ethical considerations and consent for participants: Ethical clearance was obtained from the Institutional Ethical Review Board (IERB) of the University of Gondar, College of Medicine and Health Sciences, Institute of Public Health 
(Reference №: IPH/296/2018). Those academic staff in the University of Gondar, who were selected to participate were informed about the purpose of the study, the importance of their participation and possibility of withdraw at any time. Informed written consent was obtained prior to data collection. Privacy and confidentiality of information given by each respondent were kept properly, and personal identifiers were removed. There were no risks due to participation in this research project. The collected data were used for this research purpose only and kept with complete confidentiality.

\section{RESULTS}

Socio-demographic characteristics of study participants: In this study, a total of 490 study participants responded with a response rate of $91.6 \%$. Of the respondents, $77.8 \%(\mathrm{~N}=388)$ were males with a mean age of $30.00(\mathrm{SD} \pm 3.96)$ years, which ranges from $21-52$ years. Nearly half, $48.6 \%(\mathrm{~N}=238)$ of the participants were married. The majority, $70.8 \%(\mathrm{~N}=347)$, of the study participants were lecturers by academic rank and about $35.9 \%(\mathrm{~N}=176)$ of them had greater than 4 years of working experiences (Table 1).

Table 1: Socio-demographic characteristics of participants, University of Gondar, Ethiopia, 2018

\begin{tabular}{lll}
\hline Variables (N=490) & Frequency & Percent \\
\hline Sex & & \\
$\quad$ Male & 381 & 77.8 \\
$\quad$ Female & 109 & 22.2 \\
Age & & \\
$\quad<28$ & 143 & 29.2 \\
$28-30$ & 113 & 23.1 \\
$31-33$ & 136 & 27.8 \\
$\quad$ above 33 & 98 & 20.0 \\
Academic Rank & & \\
$\quad$ Assistance lecturer & 102 & 20.8 \\
$\quad$ Lecturer & 347 & 70.8 \\
$\quad$ Assistance professor and above & 41 & 8.4 \\
Marital status & & \\
$\quad$ Married & 238 & 48.6 \\
$\quad$ Single & 235 & 48.0 \\
Divorced/Separated/ Widowed & 17 & 3.4 \\
Support responsibility for others & & 89.8 \\
$\quad$ Yes & 440 & 10.2 \\
$\quad$ No & 50 & \\
Work experience & & 26.7 \\
$\quad<2$ & 131 & 37.3 \\
2-4 & 183 & 35.9 \\
$\quad>4$ & 176 & 3.7 \\
Salary in ETB & & 30.8 \\
$<6000$ & 18 & 54.3 \\
6000-8499 & 151 & 11.2 \\
8500-10500 & 266 & \\
$\geq 10501$ & 55 & \\
\hline
\end{tabular}

ETB=Ethiopian Birr 
Table 2 presents the organizational characteristics of the study participants. Most of the study participants reported good staff relations, 91.8\% $(\mathrm{N}=450)$. Two hundred and 18 respondents $(44.5$
\%) reported high job demand. About a quarter of participants reported having low control of their jobs $(22.4 \%)$.

Table 2: Organizational characteristics of study participants in University of Gondar, northwest Ethiopia, 2018

\begin{tabular}{lll}
\hline Variables (N=490) & Frequency (n) & Percent (\%) \\
\hline Job demand & 272 & 55.5 \\
Low & 218 & 44.5 \\
High & & \\
Job control & 380 & 77.6 \\
$\quad$ High & 110 & 22.4 \\
Low & & \\
Relationships & 450 & 91.8 \\
$\quad$ Good & 40 & 8.2 \\
Poor & & \\
Role ambiguity & 412 & 84.1 \\
Low & 78 & 15.9 \\
High & & \\
Job changes & 473 & 96.5 \\
Low & 17 & 3.5 \\
High & & 77.8 \\
Support & 381 & 22.2 \\
High & 109 & \\
Low & & \\
\hline
\end{tabular}

Prevalence and factors associated with workrelated stress: The overall prevalence of workrelated stress among academic staff at the University of Gondar was found to be $60.4 \%$ [95\% CI $(57.4,63.5)]$. In the bivariate logistic regression analysis, gender, age, academic rank, work experience, job demand, job control, relationships with staffs, role ambiguity, job change, support, and cigarette smoking were variables selected for the final model. After controlling possible confounders in the multivariable regression model, age $<28$ years [AOR: 0.25 ; 95\% CI $(0.10,0.63)$ ], smoke cigarettes [AOR: 2.84; 95\% CI (1.25, 6.50)], low job control [AOR: 2.25; 95\% CI (1.21, 4.20)] and high job demand [AOR: 3.27 ; $95 \% \mathrm{CI}=$
$(2.05,5.21)]$ were found to be associated with work-related stress.

Participants smoking cigarettes were 2.84 times more probable to experience WRS than nonsmokers [AOR: 2.84; 95\% CI $(1.25,6.50)]$. The likelihood of WRS among participants $<28$ years of age was $75 \%$ lower than those $>33$ years [AOR: $0.25 ; 95 \%$ CI $(0.10,0.63)]$. The chances of developing WRS were 3.27 times higher among academic staff with high job demand compared to their counterparts [AOR: 3.27; 95\% CI (2.05, 5.21)], and the odds of WRS were 2.25 times higher among those unable to control jobs [AOR: 2.25; 95\% CI $(1.21,4.20)$ ] (Table 3). 
Table 3: Factors associated with work-related stress among academic staffs at University of Gondar, Ethiopia $2018(\mathrm{n}=490)$

\begin{tabular}{|c|c|c|c|c|}
\hline \multirow[t]{2}{*}{ Variables } & \multicolumn{2}{|c|}{ Work-related stress } & \multirow[b]{2}{*}{ COR with $95 \%$ CI } & \multirow[b]{2}{*}{ AOR with $95 \%$ CI } \\
\hline & Not stressed (\%) & Stressed $(\%)$ & & \\
\hline \multicolumn{5}{|l|}{ Sex } \\
\hline Male & $154(40.4)$ & $227(59.6 \%)$ & 1 & \\
\hline Female & $40(36.7 \%)$ & $69(63.3 \%)$ & $1.17(0.75,1.82)$ & $1.63(0.91,2.92)$ \\
\hline \multicolumn{5}{|l|}{ Age } \\
\hline less than 28 & $73(51.0 \%)$ & $70(49.0 \%)$ & $0.37(0.21,0.63)$ & $0.25(0.10,0.63)^{* *}$ \\
\hline $28-30$ & $43(38.1 \%)$ & $70(61.9 \%)$ & $0.62(0.35,1.11)$ & $0.63(0.28,1.40)$ \\
\hline $31-33$ & $51(37.5 \%)$ & $85(62.5 \%)$ & $0.63(0.36,1.113)$ & $0.52(0.25,1.10)$ \\
\hline above 33 & $27(27.6 \%)$ & $71(72.4 \%)$ & 1 & \\
\hline \multicolumn{5}{|c|}{ Work experience(in years) } \\
\hline Less than 2 & $50(38.2 \%)$ & $81(61.8 \%)$ & $0.72(0.45,1.16)$ & $0.61(0.25,1.47)$ \\
\hline $2-4$ & $90(49.2 \%)$ & $93(50.8 \%)$ & $0.46(0.30,0.71)$ & $1.06(0.40,2.80)$ \\
\hline Above 4 & $54(30.7 \%)$ & $122(69.3 \%)$ & 1 & \\
\hline \multicolumn{5}{|l|}{ Smoke cigarette } \\
\hline smoker & $11(19.6 \%)$ & $45(80.4 \%)$ & $2.98(1.50,5.92)$ & $2.84(1.25,6.50)^{* *}$ \\
\hline Non-smoker & $183(42.2 \%)$ & $251(57.8 \%)$ & 1 & \\
\hline \multicolumn{5}{|l|}{ Job demand } \\
\hline Low job demand & $144(52.9 \%)$ & $128(47.1 \%)$ & 1 & \\
\hline High job demand & $50(22.9 \%)$ & $168(77.1 \%)$ & $3.78(2.55,5.61)$ & $3.27(2.05,5.21)^{* * *}$ \\
\hline \multicolumn{5}{|l|}{ Control of job } \\
\hline Able to control & $174(45.8 \%)$ & $206(54.2 \%)$ & 1 & \\
\hline Unable to control & $20(18.2 \%)$ & $90(81.8 \%)$ & $3.80(2.25,6.43)$ & $2.25(1.21,4.20)^{* *}$ \\
\hline \multicolumn{5}{|l|}{ Relationships } \\
\hline Good & $185(41.1 \%)$ & $265(58.9 \%)$ & 1 & \\
\hline Poor & $9(22.5 \%)$ & $31(77.5 \%)$ & $2.41(1.12,5.17)$ & $0.78(0.31,1.98)$ \\
\hline \multicolumn{5}{|l|}{ Role ambiguity } \\
\hline No & $178(43.2 \%)$ & $234(56.8 \%)$ & 1 & \\
\hline Yes & $16(20.5 \%)$ & $62(79.5 \%)$ & $2.95(1.64,5.28)$ & $1.80(0.91,3.60)$ \\
\hline \multicolumn{5}{|l|}{ Job Change } \\
\hline Low & $189(40.0 \%)$ & $284(60.0 \%)$ & 1 & \\
\hline High & $5(29.4 \%)$ & $12(70.6 \%)$ & $1.60(0.55,4.60)$ & $1.10(0.29,4.24)$ \\
\hline \multicolumn{5}{|l|}{ Support } \\
\hline high support & $163(42.8 \%)$ & $218(57.2 \%)$ & 1 & \\
\hline low support & $31(28.4 \%)$ & $78(71.6 \%)$ & $1.88(1.18,2.99)$ & $1.24(0.69,2.23)$ \\
\hline
\end{tabular}

AOR: Adjusted odds ratio, CI: confidence interval, COR: crudes odds ratio, ${ }^{*}$ statistically significant at $p<0.05$, $*_{*}^{*}$ statistically significant at $p<0.001, * * *$ statistically significant at $p<0.0001$, Hosmer and Lemeshow test $=$ 0.951 showed that the model fitted well

\section{DISCUSSION}

This study employed an institution-based crosssectional design to investigate the prevalence and factors associated with work-related stress. The results indicated that $60.4 \%$ of the participants experienced work-related stress. The high prevalence of work-related stress in the current study could be due to the discrepancy, as a developing country, between high academic demands and low coping strategies. Moreover, students' misbehavior and the dynamic interaction

DOI: http://dx.doi.org/10.4314/ejhs.v30i2.10 
between the person and their work environment may trigger a negative psychological state. Besides, low control over aspects of work and cigarette smoking increased the risk of work-related stress.

The current finding was comparatively similar to the study reported in Malaysia (60.8\%) (23). This similarity might be due to the similarities in staffing, work relationship, job demand and university infrastructure between these universities. The result of this study was, however, greater than the results of other studies conducted in Malaysia $(25.9 \%)(24)$ and Ethiopia (28.2\%) (19). This difference might be due to the differences in individual coping strategies and organizational behavior between countries. Those universities might have better stress management strategies, organizational commitment and relationships within the staff.

In contrast to our findings, a number of studies reported remarkably higher stress prevalence, such as in China(91.0\%)(7), India,(74\%)(25), Tanzania, (75\%) (11), Nigeria, (75.8\%)(10), and Botswana $(81.0 \%)$ (26). The disparities in prevalence rate among these studies might be the result of the different systems of education, different specific local characteristics such as mentality, the standard of living and cultures available in these countries that might have given different perceptions to the work-related stressors (27). In addition, the difference is perhaps due to different methods, study periods and populations of the studies.

This study showed that gender, work experience, job relationship, role ambiguity, job change and support had insignificant associations with work-related stress. Similarly, the study conducted in Palestine among teachers showed no statistically significant differences in terms of variables like gender and work-experience (28). The study conducted on Zimbabwe University lecturers was also reported that there was no significant association between gender and workrelated stress (9). However, studies on gender differences have reported controversial results. For instance, early research has suggested that gender might be an important demographic characteristic to be considered in workplace stress research. Some researches show that stress is prevalent among men as compared to women(29). Despite this, study reported that female teachers tend to complain more about stress than male teachers(30). However, other researchers failed to find any significant gender differences in their studies (31).

On the other side, other study showed that job relationships and support a statistically significant association with work-related stress (32). This result indicates that people with high level of social and work support are physically and psychologically healthier than those without. Moreover, job change and role conflict/ambiguity were reported as important predictors of workrelated stress. Such changes cause a feeling of inequity and uncertainty. In addition, changes in terms and conditions without consultation were a stressor to lecturers (9).

The current study revealed that WRS was associated with job demand. This finding was in line with the findings of other similar studies in Malaysia (24) and Tanzania(11). This could be due to the fact that intensive work prolongs the high workload, interferes with leisure activities, causes too much physical and mental fatigue to perform to the best of their abilities, thereby increasing stress hormones (33). Indeed, possibly because of that, teachers have mainly indicated heavy workloads that encompasses teaching, research and community service activities (7).

The multivariable logistic regression analysis also revealed significant associations of job control and WRS. The findings of other studies in South African (34) and Malaysian (17) higher education institutions support the findings of this study. The probable reason is that academics in higher education routinely have several roles at the same time, making them unable to control their work, which in turn triggers stress (35). Also, it could be because workers who can take initiatives or decide on work perceive their work as controlled and are less likely to be stressed than people without control.

Also, this study showed that cigarette smoking was significantly associated with WRS. Research into smoking and stress has shown that instead of helping people to relax, smoking actually increases stress. This finding was aligned with the results of a research in the U.S (18) and a worldwide perspective survey in Europe, Africa and Asia (36). 
This may be due to the reality that workplace stress acts as a negative occupational exposure to poor health practices, including smoking (37). Indeed, smoking is often reported by smokers as helping people to control their mood and reduce adverse effects when they face stressors (38).

Furthermore, this study showed that age was negatively associated with WRS. The findings of other study support our result (39). The possible explanation for these findings could $b$ e the difference between young people and older pe ople's ability to cope with WRS. Even though there is a great deal of individual variability, age-related differences are evident in the nature of stressors that are likely to encounter emotional and physiological responses to stress (40).

Though this study was able to provide important data on work-related stress among academic staff, several limitations are noted. Since this study was a self-reported questionnaire-based cross-sectional study, the possibility of under or over-reporting could not be ruled out. In addition, the findings of the study only apply to the academic staff of the University of Gondar. Despite these limitations, we believe that the study provided a reasonably accurate assessment of work-related stress and associated risk factors among academic staff in the studied university.

In conclusion, this study showed that the overall prevalence of work-related stress was found to be high. The most important independent risk factors identified by a multivariable logistic regression model were: job demand, job control, age and cigarette smoking, which were associated with WRS. Furthermore, higher emphasis is required on job demand, job control and cigarette smoking to ease the burden of work-related stress factors. Workplace control programs for health risks, such as smoking cigarettes, are also vital for tackling the problem. Therefore, this research recommends that institutions of higher education work better to identify other sources of workrelated stress such as working conditions and further large-scale research.

\section{ACKNOWLEDGMENTS}

The authors acknowledge data collectors, supervisors, study participants, and the University of Gondar for their creditable contributions to the success of this research.

\section{REFERENCES}

1. Fink G. Stress: definition and history. Stress science: neuroendocrinology. 2010:3-9.

2. Kinman G, Wray S. Taking its toll: rising stress levels in further education. Available at: https://www.ucu.org.uk/media/7264/UCUstress-survey 2014/pdf/ucu_festressreport14.pdf. Accessed on 15 September 2019: UCU Publications.; 2014.

3. Panatik S, Rajab A, Shaari R, Shah IM, Rahman H, Badri S, editors. Impact of workrelated stress on well-being among academician in Malaysian Research University. International conference on education and management innovation; 2012.

4. Newberry M, Allsop Y. Teacher attrition in the USA: The relational elements in a Utah case study. Teachers and Teaching. 2017;23(8):863-80.

5. Skaalvik EM, Skaalvik S. Job Satisfaction, Stress and Coping Strategies in the Teaching Profession-What Do Teachers Say? International education studies. 2015;8(3):181-92.

6. Kinman G, Wray S. Higher stress: A survey of stress and well-being among staff in higher education. London: 2013.

7. Sun $\mathrm{W}, \mathrm{Wu} \mathrm{H}$, Wang L. Occupational stress and its related factors among university teachers in China. Journal of occupational health. 2011;53(4):280-6.

8. Reddy GI, Poornima, R. Occupational Stress and Professional Burnout among the University Teachers in South India. International Journal of Educational Planning \& Administration. 2012;2(2):109-24.

9. Masuku S, Muchemwa S. Occupational stress among university lecturers: A case of Zimbabwe. US-China Education Review. 2015;5(4):258-66.

10. Ofoegbu F, Nwadiani M. Level of Perceived Stress Among Lectures in Nigerian 
Universities. Journal of instructional psychology. 2006;33(1):66-74.

11. Mkumbo K. Prevalence of and Factors Associated with Work Stress in Academia in Tanzania. International Journal of Higher Education. 2014;3(1):1-11.

12. Hassard J, Teoh K, Visockaite G, Dewe P, Cox T. The cost of work-related stress to society: A systematic review. Journal of occupational health psychology. 2018;23(1):1-17.

13. The American Institute of Stress. Workplace Stress. 2018. Avaliable at: https://www.stress.org/workplace-stress. Accessed on 25 March 2018.

14. Buckley P. Stress-related and Psychological Disorders in Great Britain 2014. London: 2014.

15. La Torre G, Sestili C, Mannocci A, Sinopoli A, De Paolis M, De Francesco S, et al. Association between Work Related Stress and Health Related Quality of Life: The impact of socio-demographic variables. A cross sectional study in a region of central Italy. International journal of environmental research and public health. 2018;15(1):159.

16. Omoniyi MBI. Sources of workplace stressors among university lecturers in South West Nigeria: implication for counselling. European Scientific Journal. 2013;9(19):58996.

17. Mukosolu O, Ibrahim F, Rampal L, Ibrahim N. Prevalence of job stress and its associated factors among Universiti Putra Malaysia staff. Malays J Med Health Sci. 2015;11(1):27-38.

18. Slopen N, Kontos EZ, Ryff CD, Ayanian JZ, Albert MA, Williams DR. Psychosocial stress and cigarette smoking persistence, cessation, and relapse over 9-10 years: a prospective study of middle-aged adults in the United States. Cancer Causes \& Control. 2013;24(10):1849-63.

19. Yeshaw Y, Mossie A. Depression, anxiety, stress, and their associated factors among Jimma University staff, Jimma, Southwest Ethiopia, 2016: a cross-sectional study. Neuropsychiatric disease and treatment. 2017;13:2803-12.
20. Melchior M, Niedhammer I, Berkman L, Goldberg M. Do psychosocial work factors and social relations exert independent effects on sickness absence? A six year prospective study of the GAZEL cohort. Journal of Epidemiology \& Community Health. 2003;57(4):285-93.

21. Jeon SW, Kim YK. Application of Assessment Tools to Examine Mental Health in Workplaces: Job Stress and Depression. Psychiatry Investigation. 2018;15(6):553-60.

22. Wami SD, Demssie AF, Wassie MM, Ahmed AN. Patient safety culture and associated factors: A quantitative and qualitative study of healthcare workers' view in Jimma zone Hospitals, Southwest Ethiopia. BMC health services research. 2016;16(1):495.

23. MZ NA, Huda B, Hejar A. Job Stress And Its Determinants Among Academic Staff In A University In Klang Valley, Malaysia. International Journal of Public Health and Clinical Sciences. 2016;3(6):125-36.

24. Ismail $\mathrm{N}$, Rahman AA, Abidin EZ. Organizational Factors Associated with Occupational Stress among Lecturers in Community Colleges, Peninsular Malaysia. Iranian Journal of Public Health. 2015;43(3):125-30.

25. Reddy GL, Poornima R. Occupational stress and professional burnout of University teachers in South India. International Journal of Educational Planning \& Administration. 2012;2(2):109-24.

26. Fako TT. Occupational stress among university employees in Botswana. European Journal of Social Sciences. 2010;15(3):31326.

27. Stoner J, Perrewé P. Consequences of depressed mood at work: The importance of supportive superiors. Stress and quality of working life: current perspectives in occupational health. 2006:87-100.

28. Oteer R. Stress at Work and Its Subsequent Problems among Teachers of the Public Schools Which Operate the School-Based Violence Reduction Program (VRP) in Tulkarm Governorate. World Journal of Education. 2015;5(4):26-37. 
29. Eres F, Atanasoska T. Occupational stress of teachers: A comparative study between Turkey and Macedonia. International Journal of Humanities and Social Science. 2011;1(7):59-65.

30. Ravichandran R, Rajendran R. Perceived sources of stress among the teachers. Journal of the Indian Academy of Applied Psychology. 2007;33(1):133-6.

31. Shkëmbi F, Melonashi E, Fanaj N. Workplace stress among teachers in Kosovo. SAGE Open. 2015;5(4):2158244015614610.

32. Barabanshchikova VV, Meshkova PR, Surova DN. Comparison of stress level among school teachers in the period of organizational changes. Procedia-social and behavioral sciences. 2014;146:375-80.

33. Dahlgren A, Kecklund $G$, Åkerstedt $T$. Overtime work and its effects on sleep, sleepiness, cortisol and blood pressure in an experimental field study. Scandinavian Journal of Work, Environment and Health. 2006;32(4):318-27.

34. Zhuwao S, Setati ST. Demographic differences, occupational stress and organisational commitment among employees in higher education institution. Journal of Governance and Regulation. 2015;4(4-3):65868.

35. Poalses J, Bezuidenhout A. Mental Health in Higher Education: A Comparative Stress Risk Assessment at an Open Distance Learning
University in South Africa. International Review of Research in Open and Distributed Learning. 2018;19(2):169-91.

36. Stubbs B, Veronese N, Vancampfort D, Prina AM, Pao-Yen L, Tseng P-T, et al. Perceived stress and smoking across 41 countries: A global perspective across Europe, Africa, Asia and the Americas. Scientific Reports (Nature Publisher Group). 2017;7(1):1-8.

37. Bickford M. Stress in the Workplace: A General Overview of the Causes, the Effects, and the Solutions. Canadian Mental Health Association Newfoundland and Labrador Division. 2005:1-3.

38. Aronson KR, Almeida DM, Stawski RS, Klein LC, Kozlowski LT. Smoking is associated with worse mood on stressful days: results from a national diary study. Annals of Behavioral Medicine. 2008;36(3):259-69.

39. Götz S, Hoven H, Müller A, Dragano N, Wahrendorf M. Age differences in the association between stressful work and sickness absence among full-time employed workers: evidence from the German socioeconomic panel. International archives of occupational and environmental health. 2018;91(4):479-96.

40. Novais A, Monteiro S, Roque S, CorreiaNeves M, Sousa N. How age, sex and genotype shape the stress response. Neurobiology of Stress. 2017;6:44-56. 